\title{
Identification of User Needs Priorities for Landscape Design
}

\author{
Nabil Ibrahim El-Sawalhi", Aisha Nasr Al-yazgi \\ Civil Engineering Department, Faculty of Engineering, The Islamic University of Gaza, Gaza, Palestine \\ Email address: \\ nsawalhi@iugaza.edu.ps (N. I. El-Sawalhi), aisha.n.yazgi@hotmail.com (A. N. Al-yazgi) \\ ${ }^{*}$ Corresponding author
}

To cite this article:

Nabil Ibrahim El-Sawalhi, Aisha Nasr Al-yazgi. Identification of User Needs Priorities for Landscape Design. Landscape Architecture and Regional Planning. Vol. 4, No. 4, 2019, pp. 72-80. doi: 10.11648/j.larp.20190404.12

Received: November 13, 2019; Accepted: December 2, 2019; Published: December 11, 2019

\begin{abstract}
Quality of landscape can be used as an indicator to measure the life levels, contribute to the reduction of pollution, provide a human health positively, and many benefits like aesthetic, psychological, and social. This quality can be achieved when meeting the individuals needs and their requirements. The general list of objectives for all landscape must be determined according to user needs and planning methods. The main purpose is to identify the user needs in landscape design process. The Islamic university of Gaza (IUG) was used as case study. The male and female students ' priorities have been identified. The study used a quantitative data. The extensive literature review was done to identify the landscape design elements. A focus group from the university students was conducted to identify the IUG students' needs which used to build the questionnaire. Consulting 6 experts to pre-test the questionnaire. The questionnaire targeted group is IUG students. The data were analyzed for testing statistical validity and reliability using SPSS. The softscape and hardscape elements were identified and the degree of quality implementation in both campuses "male and female". The results confirmed that, the degrees of quality implementation in male campus was more than female. The results of the questionnaire showed that, the male and female students have the same needs in the campus except "festivals and events, external cafeteria, and drinking". The most ten important needs the student required are "cleanliness, praying, feeling safe, feeling comfortable psychic, drinking, spaciousness and breadth, shading, quiet, rest and sitting, and fresh air". Originality: This study will contribute significantly to consider public participation as a way in collecting the VOC customers.
\end{abstract}

Keywords: Landscape Design, Quality Landscape, Users Needs

\section{Background}

Quality of landscape can be used as an indicator to measure low or high quality of the life levels. Thus, the quality of life evaluation has a big challenge from many indicators that must be defined [1]. In addition, green spaces management is important in urban landscape planning and contributes to the city's image. Landscape concept has become widely accepted for embracing the natural sphere as well as human activities and heritage to guide decisions towards more integrated and sustainable management practices [2].

Landscapes can be defined as "key factor in the physical, mental and spiritual well-being of individuals and societies", that they are an important part of nature and quality of the environment [3].

Quality standard related to landscape will be led to high quality. Failure or lack of reliability in any standard leads to failure to achieve or monitor quality. Quality of landscape construction can also be achieved when matching or meeting the individual's needs and their requirements. The individuals play a large and effective role in the management and planning of landscape, which has an important element of the environment [4].

The urban outdoor spaces contribute to the reduction of various types of pollution and contribute positively to human health and well-being. In addition to the aesthetic, psychological and health benefits can have other social benefits [5].

Landscape quality is often covering a wide range of environmental, ecological, socio-cultural and psychological 
factors [6]. The transfer project knowledge and motivation to local stakeholders' influence and contribute to the quality of landscape [3].

The characteristics of the identified landscapes, modification and their values by involved parties and the population concerned are important in the formulation of landscape quality objectives. As these objectives were determined and formulated based on each landscape that identified and evaluated. There can be no published general list of objectives for all landscapes but must be determined by each landscape or as user needed and planning [3].

Landscape provide many benefits to individuals, for example, exterior green open spaces contribute in human health, well-being, aesthetic benefits, psychological, natural features, social benefits and it leads to thermal comfort. Besides, the outdoor spaces have special environmental importance in reduction types of pollution and to the improvement of climatic conditions [5].

In modern cities, the most requirement for a human is a healthy environment to live in high satisfaction and well, therefore it must protect and develop the landscape or outdoors open space because it has strong associated with this requirement [6]. The economic and social changes effect on how the use of landscape spaces and formation. There is increasing growth population in the world, that lead to the change of city image and an increase in the demand for facilities and infrastructure projects [7]. In addition to that, the city will become as reinforced concrete and uncomfortable life [8]. That will generate problems in lands and lack of open spaces which leads to a lack of social activities [9]. The ensuring public participation in planning and designing open spaces creates a positive impact of increasing use of such spaces. In addition to the users' observation of how they have used the space and measuring their preferences to design a successful space [10].

Landscape design in Gaza city suffers from many problems that led to low quality. Although most projects design in Gaza Strip takes a long time in the design phase, the landscape is neglected and designed in a random manner. This will lead to a lack of landscape elements to be consistent with surrounding. The project designer doesn't take into consideration the needs of the end-users and ignores their participation in expressing their opinion or needs. But the designer focuses only on the purpose of the project. In addition, he focuses on the aesthetics of the final form without considering the landscape elements function, environmental, social purposes, and public needs.

The appropriate design has many benefits especially on the performance of users. The researcher focuses on the study of landscape projects using HOQ tool which is an important tool that could assess the user's need and guide the designer to focus on the most important demonstrated landscape elements.

The aim is to develop a HOQ as a model to improve the quality management system in the landscape design process. The study is focusing on the IUG campus and evaluating the current status and the level of quality implementation of landscape design. Also the study to identify students' needs in the campus landscape.

\section{Landscape Elements}

The landscape elements divided into softscape, hardscape, and water elements. These elements essential to balance in landscape design and contribute to building the beauty for city's image by using different types of plant, shade trees, grass and water bodies. The soft landscape is some difficulty in landscape design. A good landscape should attention, especially in softscape elements selection. It consists of many types with different functions such as plant, lawns and ground covers [11].

Plant: is the most important elements in the landscape design. In recent years it has become some problems by choices the plant in randomly and neglects the climate and soil characteristics. The designer focuses only on the image without taking into consideration the site characteristics of getting only the surface form and the final image of the space [12].

Lawns and ground covers: are the basic element in landscape design. It links the other softscape elements such as trees, shrubs, and flowers. Lawns also provide spiritual comforts for space and an escape from the solid surfaces of walkways. A good lawn directly influences landscape activities. However, no other ground cover is as strong underfoot as a grass lawn [13].

\section{Factors Affecting Landscape Space Design}

The landscape is influenced by many variables like geographical environment, political, cultural, social, technological, and economic factors in addition to the experience, sensation, familiarity, population's needs, and personal characteristics such as age and gender. There are different types of landscape spaces that have different functions like a public garden, urban squares spaces, games playgrounds, yards, parks, and outdoors spaces of public institutes like education or health [14]. The landscape types range of many styles like a roof garden, greenway, and institute area for hospital grounds or schoolyard, residential neighborhoods, and parks [15].

The users' characteristics are factors which affect the use of landscape spaces [16]. The quality of landscape design depends on design open space areas which achieve the users' expectations and needs. It is different from small or large scales, on a smaller scale like house garden which is used by specific people, or in large scale, is used by different age groups [14]. The needs and expectations in landscape space essential to planning and design the formation and direct it [17]. These needs and expectations change according to the users ' personal preferences, cultures, and environments [14].

Landscape aims to space which benefits people to improve quality of life and meet their requirements and expectations 
[18]. It is supposed to achieve all recreational, social, and cultural needs in order to be favorite and to satisfy for its users, that lead to improving the user's quality life [19].

The nature needs: It is referring to achieve users' needs by the natural environment [15] and it is preferring the environment space to be less complex which it leads the users to be relaxation and more sociable [19]. This category includes to contact with nature, aesthetic preference and recreation and play.

Human interaction needs: It is referring to achieve users' needs which focus on human interactions that the environment has less role [15]. This category includes to social interaction and privacy, sense of community identity, and citizen participation in the design process.

Information landscape spaces, public participation is crucial [20], it integrates the local community groups in the early time of planning or and design process [15]. It helps in to achieve a sustainable space through allowed the citizens to evaluate their needs [21]. The participation process will give useful results and it controls the community over their lives [14]. So that to develop landscape not only focus on reserve landscape resources, but it should guarantee the citizen participation in the design process [5].

\section{Research Methodology}

The research was carried out in Gaza City and targeted the IUG students who study at university in semester 2017 to 2018 . A focus group from the university students to identify the students' needs in campus landscape in Islamic University was conducted. Six experts were consulted from architecture and construction management academic associated doctors to pretest the questionnaire, then it was modified before a final form was produced. The questionnaire targeted sample of IUG students. The population is the IUG students includes 20,000 students and approximately from male $48 \%$ as 7600 students and approximately from female $62 \%$ as 12400 students [22]. The size sample was calculated using Equation $1 \& 2$.

$$
\begin{aligned}
& n_{o}=\frac{Z^{2} p q}{e^{2}} \\
& n=\frac{n_{0}}{1+\frac{\left(n_{0}-1\right)}{N}}
\end{aligned}
$$

Where: $n$ : is the sample size

$Z$ : $Z$ value (e.g. 1.96 for $95 \%$ confidence interval)

$p$ : Percentage expressed as decimal, (0.50 used for sample size needed)

$q:$ is $1-p$

$e$ : confidence interval expressed as decimal (0.05)

$N$ : is the population size

Based on the above equation, 377 questionnaires were distributed. 344 questioners were received with a response rate $=92.22 \%$.

A focus group was conducted with the IUG students who spend their time in the university. This FG aims to identify the students' needs. The most important needs were extracted the from students' point of view. The needs were classified into five categories by discussion with some of architectural engineers as shown in Table 1.

Table 1. The needs categories from $F G$.

\begin{tabular}{ll}
\hline Category & Student Needs \\
\hline Environmental needs & Natural enjoyment, fresh air, sunbathing, aesthetic view with flowers, shading, and cleanliness. \\
& Chatting with friends, make friendships, rest and sitting, quiet, feeling safe, feeling comfortable psychic, privacy, and \\
Social needs & spaciousness and breadth. \\
Recreational needs & Playing, walking, meditation, sport, festivals and events, and special celebrations \\
Functional needs & Reading, studying, eating food, discussions and presentations, and continue to academic. \\
Other needs & External sale, external cafeteria, praying, and drinking. \\
\hline
\end{tabular}

The questionnaire is consisting of four part: General information about campus users, Assessment the status of the softscape elements in the campus, Assessment the status of hardscape elements in the campus, Assess the requirements and expectations based on how much you need them in the campus. A pilot study for the questionnaire were conducted to test the validity and reliability. This will provide a trial copy for the questionnaire by testing the questions, the words meaning, and extract ambiguous questions, in addition to that, it is testing the techniques which used to collect data, and measuring the effectiveness of standard invitation to respondents.

To measure the internal consistency, 50 sample were selected and the correlation coefficients was calculated between the degree of each dimension and the total degree of the measure. In addition to that, the Pearson's correlation coefficient between the degree of each paragraph and the total score of its related dimension. The results that the correlation coefficients for the total measure and all its related dimension are statistically significant correlated at a level of significance ( $\mathrm{p}$-value $<0.01$ ), the correlation coefficients of the total measure and the dimensions range between 0.95 to 0.97 .

The reliability can be measured by both tests the first one is Alpha Cronbach's and the second one is Spilt- half techniques. The reliability of the overall measure Quality Management System for Landscape Design Process by calculating the Cronbach's alpha coefficient where the value of alpha is 0.95 . It indicates strongly that the measure has a high reliability and meets the requirements of applying the measure on the sample of the study.

The reliability of the Quality Management System for Landscape Design Process by using split half method as another way to test the reliability. Pearson's correlation coefficient for the whole measure is 0.87 and the SpearmanBrown formula is 0.93 . It indicates that the test has a high 
degree of reliability.

\section{Results and Discussion}

Table 2 show that most of the sample are females with percent equal $(70.9 \%)$ and $(29.1 \%)$ are males. Although the university consists of special cases such as physically, visually and hearing disabled but the researcher relied only on student without any disability results. In general, it is considered that the disabled students' and all students' have the same needs. Most of the sample age is ranging from 18 to under 25 years $(88.9 \%)$, while $(10.5 \%)$ age is changing from 25 to under 35 years, and $(0.6 \%)$ of sample age is from 35 to under 45 years.

Table 2. Sample users in the study.

\begin{tabular}{llll}
\hline Description & Categorize & No & Percent\% \\
\hline \multirow{3}{*}{ Gender } & Male & 100 & 29.1 \\
& Female & 244 & 70.9 \\
& Total & 344 & 100.0 \\
Age & From 18 to under 25 years & 306 & 88.9 \\
& From 25 to under 35 years & 36 & 10.5 \\
& From 35 to under 45 years & 2 & 0.6 \\
& Total & 344 & 100 \\
Transport mean & By foot & 25 & 7.3 \\
& By bus & 44 & 12.8 \\
& By car & 272 & 79 \\
& By bicycle & 3 & 0.9 \\
\multirow{4}{*}{ Hours spent in Campus } & Total & 344 & 100 \\
& Less than 2 hours & 44 & 12.8 \\
& From 2 to 4 hours & 40 & 11.6 \\
& From 4 to 6 hours & 117 & 34.0 \\
& More than 6 hours & 143 & 41.6 \\
\hline
\end{tabular}

The focus is on undergraduate students of Bachelor degree level who are the dominant class in the IUG. Most of the sample $(79.0 \%)$ go to university by car, while $(12.8 \%)$ by bus, $(7.3 \%)$ by foot and $(0.9 \%)$ by bicycle.

The result show that $(12.8 \%)$ of the sample spend less than 2 hours in campus, $(11.6 \%)$ spend from 2 to 4 hours in campus, while $(34.0 \%)$ spend from 4 to 6 hours in campus and $(41.6 \%)$ spend more than 6 hours in campus. It is clear that the most category which spend hours in campus is students with "more than 6 hours", so it is important to focus on their important needs.

\subsection{The Number of Times You Go to Outdoor Spaces in Campus}

The result in Table 3 show that $(62.2 \%)$ of the sample go to the outdoor spaces during the day for 1 to 2 times, while (16.5\%) go to the out spaces during the day for 2 to 4 times, (16.0\%) don't go, and (5.3\%) go to the out spaces during the day for more than 4 times.

Table 3. The number of times you go to outdoor spaces in campus.

\begin{tabular}{lll}
\hline Categorize & No & Percent\% \\
\hline 0 times & 55 & 16.0 \\
From 1 to 2 times & 214 & 62.2 \\
From 2 to 4 times & 57 & 16.5 \\
\hline
\end{tabular}

\begin{tabular}{lll}
\hline Categorize & No & Percent\% \\
\hline More than 4 times & 18 & 05.3 \\
Total & 344 & 100.1 \\
\hline
\end{tabular}

\subsection{Preferred Spaces During Free Time}

Table 4 show that $(44.2 \%)$ of the sample prefer the backyard of buildings during free time, while (41.9\%) prefer main square, and (13.9\%) prefer the squares at the entrances of the campus.

Table 4. Preferred spaces during free time.

\begin{tabular}{lll}
\hline Categorize & No & Percent\% \\
\hline Main Squares & 144 & 41.9 \\
The backyard of buildings & 152 & 44.2 \\
The squares at the entrances to the campus & 48 & 13.9 \\
Total & 344 & 100.0 \\
\hline
\end{tabular}

\subsection{Assessment of the Current Status of the IUG Campus Landscape Design}

Table 5 shows the level of the Quality Management System implementation in IUG campus landscape. Means, Standard Deviation, the Relative Weight of softscape and hardscape elements were used.

Table 5. Quality Management System Implementation.

\begin{tabular}{lllll}
\hline Dimension & Paragraph & Mean & St. D & Relative weight \% \\
\hline The first dimension: The softs-scape elements in the campus. & 10 & 32.8 & 7.2 & 65.6 \\
The second dimension: The hardscape elements in the campus. & 14 & 44.4 & 7.5 & 63.4 \\
Quality Management System Implementation & 24 & 77.2 & 13.7 & 64.3 \\
\hline
\end{tabular}

The result shows that the relative weight for the quality management system implementation in IUG campus equal 
64.3\% with mean 77.2 degree and std. deviation 13.7 degree, which means that IUG have a slightly high level of quality management system implementation. For each dimension, the results show that softscape elements are the most common dimension used with relative weight equal $65.6 \%$, then the hardscape elements with relative weight equal
$63.4 \%$.

Two independent samples T-Test is used to figure out the differences between the degrees of quality management system implementation among the students' gender (male, female) point of view, as shown in the Table 6 .

Table 6. Degree of quality management system implementation due to the students ' gender.

\begin{tabular}{|c|c|c|c|c|c|c|c|}
\hline \multirow{2}{*}{ Dimension } & \multicolumn{2}{|c|}{ Male $(\mathbf{N}=100)$} & \multicolumn{2}{|c|}{ Female $(N=244)$} & \multirow{2}{*}{ T- test } & \multirow{2}{*}{ P-value } & \multirow{2}{*}{ Towards } \\
\hline & Mean & St. D & Mean & St. D & & & \\
\hline The first dimension: The softs scape elements in the campus. & 35.5 & 6.7 & 31.7 & 7.2 & 4.612 & $0.001 * *$ & males \\
\hline The second dimension: The hardscape elements in the campus. & 47.2 & 8.1 & 43.2 & 7.0 & 4.651 & $0.001 * *$ & males \\
\hline Quality Management System in IUG Campus Landscape & 82.8 & 13.9 & 74.9 & 13.0 & 5.024 & $0.001 * *$ & males \\
\hline
\end{tabular}

** $\mathrm{P}$-value $<0.01 * \mathrm{P}$-value $<0.05 \backslash \backslash \mathrm{P}$-value $>0.05$.

There are significant differences $(\mathrm{P}$-value $<0.05)$ between the total degrees of quality management system among the students` gender (male, female). The differences towards males which means that male students see that the degrees of quality implementation are more than female students.

The male students see their campus landscape the implementation of quality are more than female students. This refers to the area of male campus is larger compared to the female area although the number of male students is 7600 and less than the number of female students of 12400 students. Therefore, female students see campus space as insufficient and don't meet their needs. In addition to that, the number of hardscape elements and furniture are sufficient to female students' numbers.

In Khalafallah 2015 [23], the students` findings disagree with this study in the softscape elements "lawns and grass" aren't enough. But this study agree in lack shaded area by trees and the paths should be cover.

There are significant differences $(\mathrm{P}$-value $<0.05)$ between the degrees of the softscape elements among the students gender (male, female). The differences towards males which means that male students see that the degrees assessment the softscape elements in the campus are more than female students unless paragraph 7 . There are no significant differences due to gender as shown in Table 7. It is clear that, the paragraph which ranked 1 and the most agreed from the male students is "Green spaces in the campus are adequately and appropriately available". The Mean equal 4.0, relative weight $79.4 \%$, T-test 3.706 , and P-value 0.001 . The Mean of students` response on this paragraph has increased at the intermediate response level which is 3 . Male students are in agreement with this result. The paragraph number 7 is ranked 5 " Trees height is appropriate and does not obscure vision". The Mean equal 3.7, relative weight 73.6\%, T-test -.041, and $\mathrm{P}$-value 0.968 . There are no significant differences between the Mean degree due to gender.

The paragraph "Water element like fountains is used well" is the least rank agreed from the male students is. The Mean equal 2.8 , relative weight $56.2 \%$, T-test 2.075 , and P-value 0.039 . The Mean of students` response has decreased at the intermediate response level which is 3 . The male students disapprove this statement.

The most agreed from the female students is "Trees height is appropriate and does not obscure vision". The Mean equal 3.7 and relative weight $73.7 \%$. The Mean of students response on this paragraph has increased at the intermediate response level which is 3 . The least agreed from the female students is "Water element like fountains is used well". The Mean equal 2.5 and relative weight $50.7 \%$. The Mean of students` response on this paragraph has decreased at the intermediate response level which is 3 . It is disapproved from the female students.

Table 7. The degree of the softscape elements among male and female students.

\begin{tabular}{|c|c|c|c|c|c|c|c|}
\hline \multirow{2}{*}{ No } & \multirow{2}{*}{ Paragraph } & \multicolumn{4}{|c|}{ Male $(\mathrm{N}=100)$} & \multicolumn{2}{|c|}{ Female $(N=244)$} \\
\hline & & Mean & Std. D & Relative wt. & Rank & Mean & Std. D \\
\hline 1 & Green spaces in the campus are adequately and appropriately available & 4.0 & 0.8 & 79.4 & 1 & 3.6 & 1.0 \\
\hline 2 & The space for relaxation areas is adequate for the number of students & 3.5 & 0.9 & 69.2 & 7 & 2.7 & 1.0 \\
\hline 3 & Paths are surrounded by plants and trees in a pleasant & 3.7 & 0.9 & 74.6 & 3 & 3.4 & 1.0 \\
\hline 4 & The amount of plantation is suitable in the outer squares & 3.9 & 0.8 & 78.0 & 2 & 3.5 & 1.0 \\
\hline 5 & Shaded areas are available to protect against the sun & 3.7 & 1.0 & 73.6 & 4 & 3.1 & 1.0 \\
\hline 6 & Attractive areas are available such as (diversity of trees, fountains, sculptures etc.) & 3.3 & 1.0 & 66.8 & 9 & 3.1 & 1.1 \\
\hline 7 & Trees height is appropriate and does not obscure vision & 3.7 & 1.0 & 73.6 & 5 & 3.7 & 0.9 \\
\hline 8 & There are plenty of green grass for sitting and relaxing & 3.4 & 1.1 & 67.6 & 8 & 3.1 & 1.1 \\
\hline 9 & There are enough spaces for outdoor meeting, study and social connection & 3.6 & 1.0 & 71.8 & 6 & 3.1 & 1.0 \\
\hline 10 & Water element like fountains is used well & 2.8 & 1.2 & 56.2 & 10 & 2.5 & 1.1 \\
\hline
\end{tabular}


Table 7. Continued.

\begin{tabular}{|c|c|c|c|c|c|c|}
\hline \multirow{2}{*}{ No } & \multirow{2}{*}{ Paragraph } & \multicolumn{2}{|c|}{ Female $(N=244)$} & \multirow{2}{*}{ T- test } & \multirow{2}{*}{ P-value } & \multirow{2}{*}{ Towards } \\
\hline & & Relative wt. & Rank & & & \\
\hline 1 & Green spaces in the campus are adequately and appropriately available & 72.0 & 2 & 3.706 & $0.001 * *$ & male \\
\hline 2 & The space for relaxation areas is adequate for the number of students & 54.3 & 9 & 6.308 & $0.001 * *$ & male \\
\hline 3 & Paths are surrounded by plants and trees in a pleasant & 67.2 & 4 & 3.367 & $0.001 * *$ & male \\
\hline 4 & The amount of plantation is suitable in the outer squares & 69.7 & 3 & 4.145 & $0.001 * *$ & male \\
\hline 5 & Shaded areas are available to protect against the sun & 61.2 & 8 & 5.288 & $0.001 * *$ & male \\
\hline 6 & Attractive areas are available such as (diversity of trees, fountains, sculptures etc.) & 61.6 & 6 & 2.134 & $0.034 *$ & male \\
\hline 8 & There are plenty of green grass for sitting and relaxing & 61.4 & 7 & 2.456 & $0.015 *$ & male \\
\hline 9 & There are enough spaces for outdoor meeting, study and social connection & 61.8 & 5 & 4.160 & $0.001 * *$ & male \\
\hline 10 & Water element like fountains is used well & 50.7 & 10 & 2.075 & $0.039 *$ & male \\
\hline
\end{tabular}

\subsection{The Hardscape Elements in the Campus}

There are significant differences $(\mathrm{P}$-value $<0.05)$ between the degrees of the hardscape elements among the students' gender (male, female) point of view. The differences towards males which means that male students see that the degrees assessment the hardscape elements in the campus are more than female students as shown in Table 8 .

The most agreed statement by the male students is "The paving material that used is durable, attractive, safe and non- slippery". In the paragraphs number $1,4,9,11,12$, and 13 which ranked $1,7,12,2,3$, and 11 respectively, there are no significant differences between the Mean degree in these paragraphs due to gender.

The least agreed from the male students is "Seats obstruct the movement and pedestrians". The most agreed from the female students is "The paving material that used is durable, attractive, safe and non-slippery". The least agreed from the female students is "Seats obstruct the movement and pedestrians". It is disapproved from the female students.

Table 8. The degree of the hardscape elements among male and female students.

\begin{tabular}{|c|c|c|c|c|c|c|c|}
\hline \multirow{2}{*}{ No } & \multirow{2}{*}{ Paragraph } & \multicolumn{4}{|c|}{ Male $(\mathbf{N}=100)$} & \multicolumn{2}{|c|}{ Female $(\mathrm{N}=244)$} \\
\hline & & Mean & Std. D & Relative wt. & Rank & Mean & Std. D \\
\hline 1 & The paving material that used is durable, attractive, safe and non-slippery & 4.0 & 0.8 & 80.6 & 1 & 4.0 & 0.8 \\
\hline 2 & The walking path are short to transferring from one building to another & 3.3 & 0.8 & 66.8 & 9 & 2.6 & 1.1 \\
\hline 3 & The movement is easy between roads and paths of bicycles and pedestrians & 3.5 & 1.0 & 69.4 & 5 & 3.2 & 0.9 \\
\hline 4 & The distribution of parking in the campus are appropriate and adequate & 3.2 & 1.1 & 64.6 & 7 & 3.3 & 0.9 \\
\hline 5 & Parking areas are annoying for you & 3.0 & 1.2 & 60.4 & 13 & 2.3 & 1.1 \\
\hline 6 & Provide seating areas that views on (trees, flowers, water element) & 3.4 & 0.9 & 68.6 & 8 & 3.2 & 1.0 \\
\hline 8 & Seats obstruct the movement and pedestrians & 2.7 & 1.1 & 53.6 & 14 & 2.3 & 0.9 \\
\hline 9 & The seating seats are used from suitable and comfortable material & 3.1 & 1.2 & 62.6 & 12 & 3.0 & 1.0 \\
\hline 10 & Provide group seating that allow to communicate comfortably with others & 3.4 & 0.9 & 68.2 & 6 & 3.0 & 1.0 \\
\hline 11 & The distribution of litter bins is appropriate and adequate & 3.9 & 0.9 & 77.0 & 2 & 3.9 & 0.8 \\
\hline 12 & $\begin{array}{l}\text { The number of litter bins are suitable for the level of activity in the outdoor } \\
\text { areas, especially in the areas of gatherings }\end{array}$ & 3.8 & 0.9 & 75.2 & 3 & 3.7 & 0.9 \\
\hline 13 & Use of signs for vehicles and facilities` uses & 3.1 & 1.0 & 62.8 & 11 & 2.9 & 1.0 \\
\hline
\end{tabular}

Table 8. Continued.

\begin{tabular}{|c|c|c|c|c|c|c|}
\hline \multirow{2}{*}{ No } & \multirow{2}{*}{ Paragraph } & \multicolumn{2}{|c|}{ Female $(N=244)$} & \multirow{2}{*}{ T- test } & \multirow{2}{*}{ P-value } & \multirow{2}{*}{ Towards } \\
\hline & & Relative wt. & Rank & & & \\
\hline 1 & The paving material that used is durable, attractive, safe and non-slippery & 79.9 & 1 & .349 & $0.727 \backslash$ & - \\
\hline 2 & The walking path are short to transferring from one building to another & 52.4 & 12 & 6.688 & $0.001 * *$ & male \\
\hline 3 & The movement is easy between roads and paths of bicycles and pedestrians & 63.5 & 5 & 2.623 & $0.009 * *$ & male \\
\hline 4 & The distribution of parking in the campus are appropriate and adequate & 65.7 & 4 & -.487 & $0.627 \backslash \backslash$ & - \\
\hline 5 & Parking areas are annoying for you & 46.8 & 13 & 5.174 & $0.001 * *$ & male \\
\hline 6 & Provide seating areas that views on (trees, flowers, water element) & 63.4 & 6 & 2.207 & $0.028 *$ & male \\
\hline 7 & Provide adequate seating areas in different areas (places of rest, corridors) & 60.2 & 7 & 4.463 & $0.001 * *$ & male \\
\hline 8 & Seats obstruct the movement and pedestrians & 45.2 & 14 & 3.312 & $0.001 * *$ & male \\
\hline 9 & The seating seats are used from suitable and comfortable material & 59.2 & 9 & 1.243 & $0.216 \backslash \backslash$ & - \\
\hline 10 & Provide group seating that allow to communicate comfortably with others & 59.5 & 8 & 3.760 & $0.001 * *$ & male \\
\hline 11 & The distribution of litter bins is appropriate and adequate & 77.0 & 2 & -.024 & $0.981 \backslash \backslash$ & - \\
\hline 12 & $\begin{array}{l}\text { The number of litter bins are suitable for the level of activity in the outdoor } \\
\text { areas, especially in the areas of gatherings }\end{array}$ & 74.2 & 3 & .472 & $0.637 \backslash \backslash$ & - \\
\hline 13 & Use of signs for vehicles and facilities` uses & 58.5 & 10 & 1.753 & $0.080 \backslash \backslash$ & - \\
\hline 14 & Use the banners that allows easy movement throughout the campus & 57.9 & 11 & 2.424 & $0.016^{*}$ & male \\
\hline
\end{tabular}




\subsection{Assessment the IUG Students` Needs}

To obtain the level of students `needs in the IUG campus landscape, Means, Standard Deviation, the Relative Weight of five dimensions were used (environmental, social, recreational, functional, and other needs).

Table 9. The degrees of students 'needs in the IUG campus.

\begin{tabular}{|c|c|c|c|c|c|}
\hline Dimension & Paragraph & Mean & St. D & Relative weight $\%$ & Rank \\
\hline Environmental needs & 6 & 22.3 & 5.5 & 74.2 & 2 \\
\hline Social needs & 8 & 30.1 & 7.2 & 75.3 & 1 \\
\hline Recreational needs & 6 & 17.9 & 5.0 & 59.7 & 5 \\
\hline Functional needs & 5 & 17.2 & 4.0 & 68.7 & 4 \\
\hline Other needs & 4 & 14.2 & 3.7 & 71.0 & 3 \\
\hline Needs in the campus & 29 & 20.34 & 19.7 & 70.1 & - \\
\hline
\end{tabular}

The result in Table 9 shows that the relative weight for students ' needs in the IUG campus equal $70.1 \%$ with mean 20.34 degree and standard deviation 19.7 degree, which means that the IUG have a slightly high level of students needs in campus.

For each dimension, the results show that the most common dimension is social needs with relative weight equals $75.3 \%$, then environmental needs with relative weight equals $74.2 \%$, then other needs with relative weight $71.0 \%$, then functional needs with relative weight equals $68.7 \%$, and finally the last rank for recreational needs with relative weight equals $59.7 \%$.

\subsection{The Level of Each Students`Needs}

The Mean of the total measurement for the first dimension (Table 10) "Environmental needs" equals 3.7 degree with relative weight equals $74.2 \%$ in the IUG, which mean that the environmental needs is important. The Mean of students' response on items range between 3.1 to 4.1 and the relative weight range between $62.7 \%$ to $82.0 \%$ which means that the level of students environmental needs are important. The environmental needs ranging between moderate to important as following sunbathing $62.7 \%$, natural enjoyment $73.8 \%$, aesthetic view with flowers $74.9 \%$, fresh air $75.7 \%$, shading $76.5 \%$ and cleanliness $82.0 \%$.

Table 10. The level of each items of student needs.

\begin{tabular}{|c|c|c|c|c|c|}
\hline Needs & Item & Mean & St. D & Relative weight $\%$ & Rank \\
\hline \multirow{7}{*}{ Environmental needs } & Natural enjoyment & 3.7 & 1.2 & 73.8 & 5 \\
\hline & Fresh air & 3.8 & 1.1 & 75.7 & 3 \\
\hline & Sunbathing & 3.1 & 1.1 & 62.7 & 6 \\
\hline & Aesthetic view with flowers & 3.7 & 1.2 & 74.9 & 4 \\
\hline & Shading & 3.8 & 1.2 & 76.5 & 2 \\
\hline & Cleanliness & 4.1 & 1.2 & 82.0 & 1 \\
\hline & Total environmental needs & 3.7 & 1.2 & 74.2 & - \\
\hline \multirow{7}{*}{ Social needs } & Make friendships & 3.3 & 1.1 & 67.0 & 8 \\
\hline & Rest and sitting & 3.8 & 1.1 & 75.9 & 5 \\
\hline & Quiet & 3.8 & 1.2 & 76.4 & 3 \\
\hline & Feeling safe & 4.0 & 1.2 & 79.2 & 1 \\
\hline & Feeling comfortable psychic & 4.0 & 1.2 & 79.1 & 2 \\
\hline & Privacy & 3.8 & 1.3 & 75.5 & 6 \\
\hline & Spaciousness and breadth & 3.8 & 1.2 & 76.6 & 4 \\
\hline \multirow{6}{*}{ Recreational needs } & Walking & 3.3 & 1.1 & 65.8 & 2 \\
\hline & Meditation & 3.4 & 1.2 & 67.2 & 1 \\
\hline & Sport & 2.9 & 1.2 & 58.9 & 3 \\
\hline & Festivals and events & 2.8 & 1.4 & 56.9 & 4 \\
\hline & Special celebrations & 2.8 & 1.4 & 56.7 & 5 \\
\hline & Total recreational needs & 3.0 & 1.3 & 59.7 & - \\
\hline \multirow{6}{*}{ Functional Needs } & Reading & 3.3 & 1.2 & 66.3 & 4 \\
\hline & Studying & 3.5 & 1.1 & 70.1 & 2 \\
\hline & Eating food & 3.7 & 1.1 & 74.4 & 1 \\
\hline & Discussions and presentations & 3.3 & 1.1 & 65.3 & 5 \\
\hline & Continue to academic & 3.4 & 1.1 & 67.4 & 3 \\
\hline & Total functional needs & 3.4 & 1.1 & 68.7 & - \\
\hline \multirow[b]{3}{*}{ Other needs } & External sale & 3.0 & 1.3 & 60.2 & 4 \\
\hline & External cafeteria & 3.3 & 1.2 & 65.2 & 3 \\
\hline & Praying & 4.0 & 1.2 & 80.0 & 1 \\
\hline
\end{tabular}


The Mean of the total measurement for the second dimension "Social needs" equals 3.8 degree with relative weight equals $75.3 \%$ in the IUG, which mean that the social needs is important. The Mean of students 'response on items range between 3.3 to 4.0 and the relative weight range between $67.0 \%$ to $79.2 \%$ which means that the level of students' social needs are important. The social needs ranging between moderate to important as following make friendships $67.0 \%$, chatting with friends $73.0 \%$, privacy $75.5 \%$, rest and sitting $75.9 \%$, spaciousness and breadth $76.6 \%$, quiet $76.4 \%$, feeling comfortable psychic $79.1 \%$ and feeling safe $79.2 \%$.

According to Khalafallah 2015 [23], in his study about "The adequacy of out spaces planning in universities for the social values". The findings showed that, both male and female students see less of privacy where the campus lacked from private spaces and areas. In addition to, they suffer from a noise during studding or reading activities. Overall, the results showed that the assessment was approved a slightly high level of social requirements.

The Mean of the total measurement for "Recreational needs" equals 3.0 degree with relative weight equals $59.7 \%$ in the IUG, which mean that the recreational needs is a moderate important. The Mean of students' response on items range between 2.6 to 3.4 and the relative weight range between $52.8 \%$ to $67.2 \%$ which means that the level of students 'recreational needs are a moderate important.

The recreational needs ranging between moderate to important as following playing $52.8 \%$, special celebrations $56.7 \%$, festivals and events $56.9 \%$, sport $58.9 \%$, walking $65.8 \%$ and meditation $67.2 \%$.

The Mean of the total measurement for the "Functional needs" equals 3.4 degree with relative weight equals $68.7 \%$ in the IUG, which mean that the functional needs are important. The Mean of students` response on items range between 3.3 to 3.7 and the relative weight range between $65.3 \%$ to $74.4 \%$ which means that the level of students functional needs are important. The functional needs ranging between moderate to important as following discussions and presentations $65.3 \%$, reading $66.3 \%$, continue to academic $67.4 \%$, studying $70.1 \%$ and eating food $74.4 \%$.

For other needs, the Mean of the total measurement for the "Other needs" equals 3.5 degree with relative weight equals $71.0 \%$, in the IUG, which mean that the other needs are important. The Mean of students response on items range between 3.0 to 4.0 and the relative weight range between $60.2 \%$ to $80.0 \%$ which means that the level of students 'other needs are important. The other needs ranging between moderate to important as following external sale $60.2 \%$, external cafeteria $65.2 \%$, drinking $78.5 \%$ and praying $80.0 \%$.

\section{Conclusions}

The study found out that the level of quality management system implementation for the IUG landscape design process is slightly poor according to $64.3 \%$ of the sample IUG campus population $(65.6 \%$ for softscape elements and $63.4 \%$ for hardscape elements). The male students see the level of quality implementation is $82.8 \%$ but the female students are $74.9 \%$.

The five main needs are: "Environmental needs, Social needs, Recreational needs, Functional needs, Other needs". But the following 24 needs are the most important needs and have Mean 3.0 to 4.1: "Cleanliness, praying, feeling safe, feeling comfortable psychic, drinking, spaciousness and breadth, shading, quiet, rest and sitting, fresh air, privacy, aesthetic view with flowers, eating food, natural enjoyment, chatting with friends, studying, continue to academic, meditation, make friendships, reading, walking, discussions and presentations, external cafeteria, and sunbathing".

The study found out that, there are no significant differences between the degrees of needs among the students' gender, which means that male and female students have the same needs in the campus. Except in other needs, there are significant differences towards females, which means that female students have a specific need more than male students specially in external cafeteria and drinking.

\section{Research Contributions}

Involving people in the planning of landscape would be of great importance.

\section{References}

[1] Gavrilidis, A. A., Ciocănea, C. M., Niță, M. R., Onosea, D. A., \& Năstase, I. I. (2016). Urban Landscape Quality Index planning tool for evaluating urban landscapes and improving the quality of life. Environment at a Crossroads: SMART approaches for a sustainable future, (pp. 155-167). Romania.

[2] Aziz, N. A. (2012). Green space use and management in Malaysia. Forest \& Landscape Research, pp. 127-157.

[3] Neugebauer, G., \& Stöglehner, G. (2013). Vital Landscapes: Landscape quality guidance. $4-20$.

[4] Bruni, D. (2016). Landscape quality and sustainability indicators. Florence "Sustainability of Well-Being International Forum". 2015: Food for Sustainability and not just food, FlorenceSWIF2015 (pp. 698-705). Italy: Elsevier B. V.

[5] Mahdavinejad, M., \& Abedi, M. (2011). Community-oriented landscape design for sustainability in architecture and planning. 2011 International Conference on Green Buildings and Sustainable Cities (pp. 337-344). Iran: Elsevier Ltd.

[6] Polat, A. T., \& Akay, A. (2015). Relationships between the visual preferences of urban recreation area areausers and various landscape design elements. Urban Forestry \& Urban Greening 14, pp. 573-582.

[7] Memluk, M. Z. (2013). Designing Urban Squares. In M. Özyavuz, Advances In Landscape Architecture (pp. 513-530). Croatia.

[8] Xu, H., \& Li, Y. (2011). Public Space Design of Resort Hotel Based on the Landscape View. China: Research Project of Guangxi Education Department. 
[9] Soemardiono, B., \& Rachmawati, M. (2018). The innovative landscape design on the old dense area based on community participation. Earth and Environmental Science. Indonesia: IOP.

[10] Turan, S. Ö., Pulatkan, M., Beyazlı, D., \& Özen, B. S. (2016). User Evaluation of the Urban Park Design Implementation with Participatory Approach Process. Urban Planning and Architecture Design for Sustainable Development (pp. 306315). Turkey: Elsevier Ltd.

[11] Chen, X. (2013, 8 16). Sports Venues and Outdoor Landscape Design. Advanced Materials Research, pp. 3600-3603.

[12] Zhang, Y. (2013). Analysis on Plant Design in Landscape Design. Applied Mechanics and Materials, pp. 2114-2117.

[13] Sahin, C. K. (2013). Lawns and Ground Covers in Landscape Design. In M. Özyavuz, Advances in Landscape Architecture (pp. 906-924). Croatia: InTech.

[14] Acar, H. (2013). Landscape Design for Children and Their Environments in Urban Context. In M. Özyavuz, Advances In Landscape Architecture (pp. 292-324). Croatia: InTech.

[15] Matsuoka, R. H., \& Kaplan, R. (2008, 30 10). People needs in the urban landscape: Analysis of Landscape And Urban Planning contributions. Landscape and Urban Planning 84, pp. 7-19. Al-Masri, N. (2017). The Islamic University of Gaza (IUG): An International University. Palestine, GAza: Resources Development Center, The Islamic University of Gaza.

[16] Chen, Y., Liu, T., Xie, X., \& Maruši', B. G. (2016). What Attracts People to Visit Community Open Spaces? A Case
Study of the Overseas Chinese Town Community in Shenzhen, China. International Journal of Environmental Research and Public Health, 1-17.

[17] Ozer, B., \& Baris, M. E. (2013). Landscape Design and Park User Preferences. World Conference on Psychology and Sociology 2012 (pp. 604-607). Turkey: Elsevier Ltd.

[18] Chang, K. G., Sullivan, W. C., Lin, Y.-H., Su, W., \& Chang, C.-Y. (2016). The Effect of Biodiversity on Green Space Users' Wellbeing-An Empirical Investigation Using Physiological Evidence. sustainability, 1049-1064.

[19] Kurdoğlu, B. C., Çelik, K. T., Kurt Konakoğlu, S. S., \& Erbaş, Y. S. (2016, 10 17). The Relationship Among User, Activity And Space of Street Furniture Placed at Kanuni CampusKaradeniz Technical University. The International Archives of the Photogrammetry, Remote Sensing and Spatial Information Sciences, pp. 19-23.

[20] Jausus, N., \& Said, I. (2014). Barriers to Participation in Neighbourhood Public Space Maintenance. International Alliance for Sustainable Urbanization and Regeneration, (pp. 225-233). Malaysia.

[21] Forooghi, M., Maleki, S. N., \& Maghsoudi, M. H. (2017). The barriers of participatory landscape design approaches based on experts' opinions. Quarterly Journal of Environmental Science, 193-216.

[22] Khalafallah, E. A. (2015). The Adequacy of Out Spaces Planning in Universities for the Social Values. Gaza, Palestine: The Islamic University of Gaza. 